\title{
Pengaruh Tekonlogi Informasi Terhadap Kepuasan Nasabah Pada Pegadaian Syariah (Studi Kasus Pada Pegadaian Syariah Di Provinsi Jambi)
}

\author{
Busriadi $^{1}$ \\ Institut Agama Islam (IAI) Yasni Bungo \\ Email : bbusriadi@gmail.com
}

\begin{abstract}
This study analyzes the effect of technology on customer satisfaction. The research problem refers to the business phenomenon of PT. Pegadaian Syariah (Persero) Tbk. In Jambi Province. This research problem is how to build customer satisfaction achieved as expected. The research objective is formulated to find answers to the flow of service quality performance. The modeling formulated in this study aims to provide a critical understanding of the concept and measurement of customer relationship management. Researchers include elements of the Effectiveness of the Variety of Technologies Offered, Easy-to-Use Technology, Appropriate Technology and Well-Functioning Technology which has significant consequences for customer satisfaction. This study used a descriptive analysis approach and quantitative methods with the aim of testing the influence of the variables studied through hypothesis testing. This study used 110 respondents and all respondents were customers of PT. Pegadaian Syariah (Persero) Tbk. In Jambi Province. The data analysis used Structural Equation Model (SEM) with Amos 22 computer program. The results of this study indicate that technology has a positive and significant impact on customer satisfaction. This study gave birth to a refinement that strengthens the justification of previous research where this research develops a study of the effect of service quality by expanding the study on customer satisfaction.
\end{abstract}

Keywords: Technology, Customer Satisfaction, Sharia Pawnshop.

\begin{abstract}
Abstrak
Penelitian ini menganalisis pengaruh teknologi terhadap kepuasan nasabah.Permasalahan penelitian merujuk pada fenomena bisnis PT. Pegadaian Syariah (Persero) Tbk. Di Provinsi Jambi.permasalahan penelitian ini adalah bagaimana membangun kepuasan nasabah tercapai sesuai harapan. Tujuan penelitian dirumuskan untuk mencari jawaban atas alur kinerja Mutu pelayanan.Permodelan yang dirumuskan pada penelitian ini bertujuan memberikan pemahaman yang kritis dalam konsep dan pengukuran manajemen hubungan pelanggan. Peneliti memasukan unsur Efektivitas Ragam Teknologi yang Ditawarkan, Teknologi yang Mudah Dipergunakan, Teknologi yang Tepat Guna dan Teknologi yang Berfungsi dengan Baik yang memiliki konsekuensi yang signifikan terhadap kepuasan nasabah. Penelitian ini menggunakan pendekatan analisis deskriptif dan metode kuantitatif dengan tujuan menguji
\end{abstract}

\footnotetext{
${ }^{1}$ Dosen Institut Agama Islam (IAI) Yasni Bungo
} 
pengaruh antar variabel yang diteliti melalui pengujian hipotesisPenelitian ini mempergunakan 110 responden dan keseluruhan responden adalah nasabah PT.Pegadaian Syariah (Persero) Tbk. Di Provinsi Jambi.Analisis data mempergunakanStructural Equation Model (SEM) dengan program komputer Amos 22. Hasil penelitianini menunjukkan bahwa teknologi berdampak positip dan signifikan terhadap kepuasan nasabah.Penelitian ini melahirkan sebuah penyermpurnaan yang bersifat memperkuat justifikasi penelitian terdahuludi mana penelitian ini mengembangkan kajian pengaruh mutu pelayanan dengan memperluas kajian terhadap kepuasan nasabah.

Kata Kunci: Teknologi, Kepuasan Nasabah, Pegadaian Syariah.

\section{A. Pendahuluan}

Sistem syariah yang memiliki misi melakukan pencegahan praktek ijon, riba, pinjaman tidak wajar lainnya, dan tujuan untuk meningkatkan kesejahteraan masyarakat, terutama golongan menengah ke bawah sesuai dengan bunyi pasal 7 PP No.103 tahun $2000^{2}$. Bank Indonesia3 sendiri menyatakan bahwa dalam mewujudkan stabilitas sistem ekonomi syariah dan kemanfaatan bagi perekonomian maka ia mendorong terjadinya sistem keuangan syariah yang kaffah dapat menggunakan sumber-sumber dana yang diatur dalam syariah dan menggunakannya sesuai syariah serta amanah dalam menjalankannya dengan cara dan tujuan yang baik.

Unit Layanan Gadai Syariah sebagai langkah awal adanya devisi khusus yang menangani kegiatan usaha syariah. Mekanisme operasional pegadaian syariah mengacu pada sistem administrasi modern, yaitu asas rasionalitas, efisiensi dan efektivitas yang diselaraskan dengan nilai Islam dan yang mempunyai bisnis mandiri yang secara struktural terpisah pengelolaannya dari usaha gadai konvensional. Pegadaian syariah mempunyai fungsi dalam beroperasi yaitu yang dijalankan oleh kantor-kantor cabang pegadaian syariah/Unit Layanan Gadai Syariah (ULGS) sebagai satu unit sebuah organisasi dibawah pembinaan divisi usaha lain perum pegadaian ${ }^{4}$.

Mekanisme operasional yang sesuai dengan sistem ekonomi Islam dalam lembaga keuangan diyakini merupakan alternatif yang memiliki keunggulan baik bagi nasabah, bank maupun lembaga keuangan non bank agar dapat terhindar dari riba.Namun permasalahan yang terjadi di lapangan tidak berhenti di sini saja, justru makin berkembang. Sebab situasi persaingan pasar yang semakin kompleks. Hal itu

\footnotetext{
${ }^{2}$ Peraturan Pemerintah Republik Indonesia Nomor 103 Tahun 2000 Tentang Perum Pegadaian, Pasal 6

${ }^{3}$ Zainuddin Ali, Hukum Perbankan Syariah (Jakarta: Sinar Grafika, 2008), h. 139

${ }^{4}$ Herry Sutanto dan Khaerul Umam, Manajemen Pemasaran Bank Syariah (Bandung: Pustaka Setia, 2013), h. 390.
} 
terlihat jelas ketika mulai bermunculnya lembaga keuangan baru dimana mereka berlomba-lomba memberikan layanan yang kian beragam dan menarik, Salah satu contoh lembaga pegadaian. Apalagi saat ini Otoritas Jasa Keuangan (OJK) telah membuka pintu bagi pihak swasta yang ingin ikut membuka usaha pegadaian. Hal itu tertuang dalam POJK No.31/POJK.05/2016 tentang usaha pegadaian ${ }^{5}$.Perusahaan Pergadaian yang diatur dan diawasi oleh OJK adalah perusahaan pergadaian pemerintah, yakni PT Pegadaian (Persero), serta perusahaan pergadaian swasta. Hingga Mei 2018, sudah 92 perusahaan pegadaian swasta yang sudah terdaftar dan Otoritas Jasa Keuangan telah memberikan izin usaha kepada 24 perusahaan pergadaian swasta. ${ }^{6}$

Berdasarkan data dan statistik yang di peroleh dari otoritas jasa keuangan kini pegadaian syariah tidak hanya akan bersaing dengan pegadaian konvensional dalam hal memberikan pinjaman kepada nasabah akan tetapi juga akan bersaing dengan pegadaian milik swasta, hal ini dapat dilihat tabel berdasarkan penyaluran pinjaman yang diberikan kepada nasabah.

Tabel 1

Pinjaman yang Disalurkan Perusahaan Pergadaian (Miliar Rp)

\begin{tabular}{|c|c|c|c|c|}
\hline Keterangan & $\begin{array}{c}\text { Juni } \\
\mathbf{2 0 1 8}\end{array}$ & $\begin{array}{c}\text { Septembe } \\
\mathbf{r ~ 2 0 1 8}\end{array}$ & $\begin{array}{c}\text { Desembe } \\
\mathbf{r ~ 2 0 1 8}\end{array}$ & $\begin{array}{c}\text { Maret } \\
\mathbf{2 0 1 9}\end{array}$ \\
\hline $\begin{array}{c}\text { Pegadaian } \\
\text { Pemerintah } \\
\text { (Konvensional) }\end{array}$ & 29.584 & 29.381 & 29.420 & 30.165 \\
\hline $\begin{array}{c}\text { Pegadaian } \\
\text { Pemerintah (Syariah) }\end{array}$ & 3.996 & 4.492 & 4.671 & 4.803 \\
\hline $\begin{array}{c}\text { Perusahaan } \\
\text { Pergadaian Swasta } \\
\text { (Konvensional) }\end{array}$ & 1.74 & 1.80 & 2.29 & 2.31 \\
\hline
\end{tabular}

Sumber : data dan statistik $0 \mathrm{JK}^{7}$

\footnotetext{
${ }^{5}$ http://www.ojk.go.id/id/regulasi/otoritas-jasa-keuangan/peraturanojk/POJK-Usaha-Pergadaian.pdf ${ }^{6}$ www.ojk.go.id

${ }^{7}$ https://www.ojk.go.id/id/kanal/iknb/datadan-statistik 29 Mei 2019. Diakses pada tanggal 29 Juni 2019
} 
Dengan adanya permasalahan tersebut pihak pegadaian syariah tentunya harus lebih siap bersaing secara kompetitif Guna menghadapi persaingan dengan pegadaian swasta, dan meninjau kembali kinerja perusahan karena semua layanan pegadaian sama sama menggunakan aspek layanan yang berorientasi customer satisfaction atau kepuasan pelanggan.upaya yang dilakukan agar mampu bersaing dan mampu bertahan ditengah banyak nya persaingan lembaga keuangan lainya adalah dengan menggunakan strategi manajemen hubungan pelanggan sebagai tugas utama pengembangan masa depan. ${ }^{8}$

kini pegadaian meluncurkan pegadaian syariah digital servis (PSDS) yang merupakan jawaban kebutuhan akan layanan yang berbasis digital, ini merupakan salah satu strategi pegadaian untuk melebarkan pangsa pasar terutama bagi generasi muda yang menginginkan pelayanan serba cepat, Teknologi sebagai keunggulan kompetitif adalah elemen dasar keunggulan bersaing yang harus diperhatikan dan dijalankan sebagai tujuan yang ingin dicapai pihak perusahaan. Teknologi sebagai process membuat setiap perusahaan mempunyai kesempatan untuk menjadi unggul dan menguasai pasar.Namun pada saat yang bersamaan perusahaan dituntut untuk menawarkan teknologi yang memenuhi harapan dan kebutuhan pelanggan. ${ }^{9}$ Oleh karena itu, pilihan pada konstruk penelitian pada teknologi sebagai salah satu sinergi terwujudnya manajemen hubungan pelanggan adalah pilihan yang benar.

Teknologi bagi sebagian perusahaan sering hanya dijadikan alat untuk membangun citra bahwa perusahaan memiliki teknologi yang terdepan. Seharusnya perusahaan dapat memanfaat teknologi tidak hanya untuk membangun citra lebih jauh perusahaan dapat mempergunakan teknologi untuk mendukung proses dan hasil bagi kinerja perusahaan ${ }^{10}$. Demikian halnya dengan model penelitian Chung et al. ${ }^{11}$, di mana telah memadukan teknologi dengan implikasi CRM.Namun masih belum menyentuh wilayah penelitian yang penting yaitu perilaku pelanggan sebagai dampak

${ }^{8}$ Payne, A,Handbook Of CRM: Achieving Excellence in Customer Management. (Great Britain: Elsevier Ltd. 2008), h. 4-6.

${ }^{9}$ Liang, et.al., "The Behavioral Sequence Of Information Education Service Industry In Taiwan: Relationship Bonding Tactics: Relationship Quality And Behavioral Loyalty ", Measuring Business Excellence, vol. 11, No. 2, 2007, h. 62-74.

${ }^{10}$ Lallmahamood and Muniruddeen, " An Examination Of Individual's Perceived Security And Privacy Of The Internet In Malaysia And Influence Of This On Their Intention To Use E-Commerce: Using An Extension Of The Technology Acceptance Model", Journal Internet Banking and Commerce, vol. 12 No. 3 , 2007, h. 1-26.

${ }^{11}$ Chung,et.al.,"An Empirical Study Of Customer Relationship Management Implementation In Taiwan's Machine Industry ”, Business and Public Affairs, vol. 1, Issue 1. 2007, h.1-12. 
BUSRIADI :Pengaruh Tekonlogi Informasi...

positip dari kinerja CRM yang baik.Pilihan dan keputusan untuk mengangkat topik penelitian yang berkaitan dengan implementasi dan hasil dari teknologi perusahaan adalah pilihan yang layak.

\section{B. Kajian Teori}

\section{Teknologi}

Yang dimaksud dengan Teknologi disini adalah pengembangan dan aplikasi dari alat, mesin, material dan proses yang menolong manusia menyelesaikan masalahnya. Istilah Teknologi sering menggambarkan penemuan alat-alat baru yang menggunakan prinsip dan proses penemuan saintifik. Teknologi juga mempunyai keunggulan, keunggulan tersebut merupakan kenyataan yang tidak dapat disangkal bahwa untuk peningkatan efisiensi, efektifitas dan poduktivitas kerja, suatu perusahaan tidak punya pilihan lain kecuali memanfaatkan berbagai kemajuan dan terobosan yang terjadi di bidang teknologi. Dalam strategi jangka panjang, para perumus strategi perusahaan biasanya menyatakan apakah perusahaan ingin memperoleh dan mempertahankan keunggulan teknologi dengan segala implikasinya ataukah puas sekedar menjadi "pengikut" dalam pemanfaatan berbagai kemajuan dan terobosan teknologi yang dilakukan oleh pihak lain. ${ }^{12}$

Pengertian teknologi informasi adalah seperangkat alat yang membantu bekerja dengan informasi dan melakukan tugas-tugas yang berhubungan dengan pemrosesan informasi. Customer Relationship Management (CRM) merupakan bagian dari Integreted Marketing Communication (IMC) yang digunakan untuk memelihara dan menciptakan loyalitas pelanggan dalam waktu yang lama dan mengikat pelanggan secara personal dengan memanfaatkan perkembangan teknologi. ${ }^{13} \mathrm{CRM}$ juga untuk membantu mengelola bisnis, pekerjaan mendapatkan, mengembangkan, dan mempertahankan pelanggandidukung oleh teknologi.

Aspek technology yaitu strategi pengembangan teknologi CRM dan proses implementasi. Perusahaan harus memilih teknologi yang baik dan tepat mendukung aspek proses. Menurut Chen dan Popovic, teknologi memainkan peran penting dalam CRM karena memungkinkan organisasi untuk mengumpulkan, menganalisis, dan mendistribusikan data pelanggan dalam perusahaan. karena kemajuan pesat di bidang teknologi, beberapa

\footnotetext{
${ }^{12}$ Sondang P, Siagian. Manajemen Stratejik,(Jakarta :Bumi Aksara,1995),h.133

${ }^{13}$ Husein Umar, Riset Pemasaran dan Perilaku Konsumen (Jakarta: JBRC, 2000), h. 39.
} 
organisasi berinvestasi dalam solusi teknologi CRM untuk mendapatkan peningkatan hubungan pelanggan. Namun penting untuk dicatat bahwa teknologi CRM harus diintegrasikan untuk membantu berbagai departemen organisasi, oleh karena itu perusahaan harus bekerja untuk mengelola teknologi secara efisien.

Hal ini terkait dengan strategi pemilihan dan pengembangan teknologi CRM.Perlu dilakukan langkah-langkah implementasi yang berbentuk pilot project terlebih dahulu, agar kelak implementasi secara menyeluruh dapat berjalan dengan sukses seperti yang diharapkan. Indikator dari variabel faktor teknologi yaitu :

1) Mempermudah Informasi pelanggan

2) Memberikan kemudahan pelayanan

3) Jaringan yang luas

4) Teknologi fasilitas pendukung.

Dampak strategis pemanfaatan teknologi informasi bagi organisasi dapat dilihat dari dapat tidaknya teknologi informasi menunjang dan membantu organisasi dalam melaksanakan dan mencapai strategi organisasi secara keseluruhan.Aplikasi teknologi CRM menghubungkan front office (sales, marketing dan customer service) dan back office (financial, operasional, logistik dan sumber daya manusia) dengan touch point.pelanggan perusahaan. ${ }^{14}$

Teknologi informasi tidak hanya mencakup perangkat komputerasi (hardware) dan aplikasi aplikasi pendukungnya (software) saja, tetapi juga sumber daya manusia yang menggunakannya (brainware). Selain itu Teknologi tidak akan berjalan sebagaimana fungsinya jika bukan manusia yang menggunakannya atau tanpa manusia Teknologi dan Komunikasi itu sendiri tidak mungkin ada, yang tentunya sebagian besar masyarakat pasti menggunakan Teknologi Informasi sebagai kepentingan akan aktivitas dan kebutuhan manusia di era ini. ${ }^{15}$

Perkembangan Teknologi Informasi di era modern saat ini tidak bisa dipungkiri lagi sangat berpengaruh besar terhadap kemudahan dan kelancaran suatu informasi atau pengolahan data dalam berbagai bidang, salah satunya dalam bidang Manajemen Sumber Daya Manusia. Dengan fungsi Teknologi Informasi sebagai pengambilan, pengumpulan, pengolahan, penyimpanan, penyebaran, dan penyajian informasi akan

\footnotetext{
${ }^{14}$ Fickel, L. "Know your customer", CIO Magazine, Vol. 12. No. 21,1999. h. 62-72

${ }^{15}$ Taliziduhu Ndraha, Budaya Organisasi, Cet. Kedua, (Jakarta: PT Rineka Cipta, 2004), h.11.
} 
BUSRIADI :Pengaruh Tekonlogi Informasi...

memudahkan proses Manajemen Personalia untuk mengatur sumber daya manusianya dengan baik dan cepat tentunya dengan meminimalisir human error yang kemungkinan terjadi. Inilah yang membuat kedua aspek ini saling keterhubungan dan tersinkronisasi.

\section{Kepuasan Pelanggan}

Kepuasan pelanggan adalah konsep kunci baik dalam praktik teori maupun pemasaran, sekaligus menjadi titik akhir utama untuk semua aktifitas bisnis. ${ }^{16}$ Definisi kepuasan pelanggan menurut Philip Kotler dan Gary Armstrong bahwa kepuasan merupakan tingkatan kinerja produk yang dianggap sesuai dengan ekspektasi pembeli tersebut. ${ }^{17}$ Adapun menurut Tim Markenis, kepuasan pelanggan adalah perasaan senang atau kecewa yang didapatkan seseorang dari membandingkan antara kinerja produk yang dipersepsikan dengan ekpektasinya. ${ }^{18}$ Bloemer, et,al., menunjukkan bahwa kepuasan dari nasabah merupakan salah satu elemen penting dalam menumbuhkan munculnya loyalitas nasabah. Kepuasan nasabah merupakan sikap setelah proses akhir dari suatu pembelian yang dibentuk secara psikologi berdasarkan perbandingan antara apa yang diharapkan dan kenyataan yang diperoleh. ${ }^{19}$

Pengertian ini lebih dapat diperjelas lagi dengan yang diungkapkan oleh Oliver bahwa kepuasan adalah tingkat perasaan seseorang (pelanggan) setelah membandingkan antara kinerja atau hasil yang dirasakan (pelayanan yang diterima dan dirasakan) dengan yang diharapkannya. Pelayanan diharapkan membuat pelanggan merasa puas (customer satisfaction) adalah dengan memberikan kepada pelanggan apa yang betul-betul mereka butuhkan dan inginkan, bukan memberikan apa yang kita pikirkan dibutuhkan oleh mereka.

Cronin et,al., menunjukkan enam konsep intidalam mengukur kepuasan pelanggan pada bidang jasa, yaitu terdiri atas

1) Kepuasan pelanggan keseluruhan, cara yang paling sederhana untuk mengukur kepuasan pelanggan adalah langsung menanyakan kepada pelanggan seberapa puasmereka terhadap jasa. Hal ini dapat dilakukan dengan cara mengukur tingkat

\footnotetext{
${ }^{16}$ Inggang Perwangsa, Nuraalam, Manajemen Hubungan Pelanggan Perbankan Syariah Indonesia. (Sleman : CV Budi Utama, 2018), h. 81

${ }^{17}$ G. Armstrong and P. Kotler, Marketing: An Introduction, (Pearson Education, Upper Saddle River, NJ, USA, 10th edition, 2011), h. 13

${ }_{18}$ Tim Markenis. Customer Satisfaction and Beyond, (Yogyakarta: Markenis, 2009), h. 11.

${ }^{19}$ Ueltschy, et. al., " Service Quality And Satisfaction: An International Comparison Of Professional Services Perceptions “, Journal of Services Marketing, Vol. 21 No. 6. 2007, h. 410-423.
} 
kepuasan pelanggan terhadap jasa perusahaan bersangkutan dan membandingkan dengan tingkatkepuasan pelanggan keseluruhan terhadap jasa para pesaing.

2) Dimensi kepuasan pelanggan (Overall customer satisfaction) umumnya proses initerdiri atas empat langkah, yaitu: mengidentifikasikan dimensi-dimensi kunci kualitas pelayanan, meminta pelanggan menilai jasa perusahaan berdasarkan itemitem spesifik,meminta pelanggan menilai jasa pesaing berdasarkan item-item spesifik yang sama, dan menentukan dimensi-dimensi yang menurut mereka paling penting dalam menilaikepuasan pelanggan secara keseluruhan.

3) Konfirmasi harapan (Confirmatiom of expectation) dalam konsep ini kepuasan tidak diukur langsung, namun dijelaskan berdasarkan kesesuaian atau ketidaksesuaian antara harapan pelanggan dengan kinerja aktual produk perusahaan pada sejumlah atribut atau dimensi penting.

4) Minat pembelian ulang (Repurchase intent) kepuasan pelanggan diukur dengan menanyakan apakah pelanggan akan berbelanja atau menggunakan jasa perusahaan kembali.

5) Kesediaan untuk merekomendasikan (Willingness to recommended) dalam kasus jasa yang pembelian ulangnya relatif lama atau bahkan hanya terjadi satu kali pembelian, kesediaan pelanggan untuk merekomendasikan jasa kepada teman atau keluarga menjadi ukuran penting untuk dianalisis dan ditindak lanjuti.

6) Ketidakpuasanpelanggan (Customer dissatisfaction) Beberapa aspek untuk mengetahuiketidakpuasan pelanggan, yaitu: keluhan,retur atau pengembalian produk, biayagaransi, penarikan kembali produk dari pasar, dan pelanggan beralih ke pesaing. ${ }^{20}$

Kotler dan Keller mengungkapkan bahwa pelanggan yang puas biasanya tetap setia untuk waktu yang lebih lama, membeli lagi ketika perusahaan memperkenalkan produk baru dan memperbaharui produk lama, membicarakan hal-hal baik tentang perusahaan dan produknya kepada orang lain, tidak terlalu memperhatikan merek pesaing, tidak terlalu sensitif terhadap harga, menawarkan ide produk atau jasa kepada

${ }^{20}$ Cronin, J. Joseph Jr. dan Taylor, Steven. 1992. "Measuring Service Quality :Reex Amination and Extension"Journal of Marketing.Vol. 56. h. 55-68. 
BUSRIADI :Pengaruh Tekonlogi Informasi...

perusahaan, dan biaya pelayanannya lebih murah dibandingkan pelanggan baru karena transaksi dapat menjadi hal rutin. ${ }^{21}$

Kotler juga mengemukakan ada 4 metode untuk mengukur kepuasan nasabah, yaitu :

1) Sistem keluhan dan saran Setiap organisasi yang berorientasi pada para pelanggan perlu memberikan kesempatan yang luas kepada para pelanggannya untuk menyampaikan saran, pendapat dan keluhan mereka. Media yang digunakan bisa berupa kotak saran yang tempatnya mudah dijangkau pelanggan atau komentar yang bisa diisi langsung maupun yang bisadikirim via pos pada perusahaan.informasi-informasi yang diperoleh melalui metode ini dapat memberikan ide-ide baru dan masukan yang berharga kepada perusahaan, sehingga memungkinkannya untuk bereaksi dengan tanggap dan cepat untuk mengatasi masalah-masalah yang timbul.

2) Ghost shopping adalah Salah satu cara untuk memperoleh gambaran mengenai kepuasan pelanggan adalah dengan memperkerjakan beberapa orang untuk berperan atau bersikap sebagai pelanggan atau pembeli potensial produk perusahaan dan pesaing. Kemudian mereka melaporkan temuan-temuannya mengenai kekuatan dan kelemahan produk perusahaan dan pesaing berdasarkan pengalaman mereka dalam pembelian produk-produk tersebut. Selain itu para ghost shopper juga dapat mengamati cara perusahaan dan pesaingnya dalam melayani permintaan pelanggan., menjawab pertanyaan pendapat dan menangani setiap keluhan.

3) Analisis pelanggan yang hilang adalah perusahaan menghubungi para pelanggan telah berhenti membeli atau yang telah pindah pemasok agar dapat memahami mengapa hal itu terjadi dan supaya dapat mengambil kebijakan perbaikan selanjutnya.

4) Survei kepuasan pelanggan adalah Perusahaan-perusahaan yang bertanggung jawab mengukur secara langsung kepuasan pelanggan dengan mengadakan survei yang teratur. Metode surveymerupakan metode yang paling banyak digunakan dalam pengukuran kepuasan pelanggan. ${ }^{22}$

\footnotetext{
2007), h. 140

${ }^{21}$ Kotler, Philip. dan Keller, Kevin Lane. Manajemen Pemasaran. Jilid 1dan 2. (Jakarta: PT Indeks,

${ }^{22}$ Philip Khotler,dkk, Dasar-Dasar Pemasaran, (Jakarta: Indonesia, 1996), h. 46
} 
Busriadi :Pengaruh Tekonlogi Informasi...

Kepuasan pelanggan, seringkali tidak ada hubungannya dengan produk atau jasa inti yang ditawarkan.Pergeseran kualitas yang muncul semula dalam produksi barang, dan akhir-akhir ini merambah ke bidang industri jasa. Sekarang pelanggan sangat mudah mendapatkan barang atau jasa dengan kualitas baik atau bahkan kualitas super.

\section{Hubungan Teknologi terhadap Kepuasaan Nasabah}

Perkembangan teknologi di era globalisasi seperti sekarang ini sudah sangat berkembang dengan pesat dan sangat canggih, perkembangan teknologi sangat berpengaruh terhadap kehidupan manusia dimasa ini maupun di masa yang akan datang, karena teknologi informasi berperan penting dikehidupan sehari-hari. Oleh karena itu manusia di era modern ini dituntut untuk mengikuti perkembangan teknologi, karena dalam dunia bisnis teknologi informasi sangat berperan penting dalam menjalankan bisnisnya, karena dengan teknologi informasi membuat dunia bisnis berkembang dengan pesat dan memudahkan dalam menjalankan bisnisnya.

Inovasi teknologi memiliki arti penting dalam kehidupan umum dan profesional manusia saat ini.Ini dapat dirasakan kegunaannya, karena keamanan dan privasi merupakan faktor utama untuk menerima sistem online.Era ini dapat dikaitkan sebagai revolusi teknologi, karena perluasan secara cepat teknologi informasi, telah menyerap ke dalam kehidupan manusia.Kemajuan teknologi yang cepat, telah memperkenalkan perubahan besar dalam suasana ekonomi dan bisnis di seluruh dunia. ${ }^{23}$

Ada tiga objek besar yang harus di capai dan menjadi target utama dari penerapan teknologi informasi;

1) Teknologi informasi secara langsung maupun tidak langsung harus memiliki dampak terhadap penciptaan produk pelayanan yang jauh lebih baik dari sebelumnya sehingga meningkatkan kinerja dan daya saing perusahaan (value adding activity).

2) Teknologi informasi harus dapat meningkatkan kualitas pengambilan keputusan dari manejemen dalan bentuk penyediaan informasi dan pengetahuan yang relevan, tepat, akurat, terpercaya, dan bernilai tinggi.

${ }^{23}$ Qureshi, T.M., Zafar, M.K. \& Khan, M.B. 2008. "Customer Acceptance Of Online Banking In Developing Economies”. Journal of Internet Banking and Commerce, Vol. 13, No.1. h. 2-9 
BUSRIADI :Pengaruh Tekonlogi Informasi...

3) Teknologi informasi harus mampu meningkatkan level perolehan pendapatan perusahaan (revenue) dengan cara memanfaatkannya untuk semakin mendekatkan perusahaan dengan para calon pelanggan. ${ }^{24}$

Dari penjelasan di atas membantu menunjukan bahwa teknologi yang di terapkan dengan baik memberikan pola tata pamong teknologi yang baik, Good IT Governance memerlukan perancangan, penerapan dan oprasi yang berhati-hati. Bahkan tidak sedikit diantara mereka yang memegang prinsip, bahwa tidak memiliki infrastruktur teknologi informasi yang baik berarti cepat atau lambat akan segera tersingkir dari dari arena persaingan. alasannya cukup mudah, yaitu karena sebuah industri jasa, yang kinerjanya sangat di pengaruhi oleh variabel ruang dan waktu.

Meningkatnya pelayanan pelanggan merupakan suatu usaha untuk menembus batasan-batasan ruang dan waktu yang dapat dilakukan dengan bantuan teknologi komputer dan telekomunikasi. Pada saat yang bersamaan, teknologi ini pula yang akan menjadi senjata bagi bank yang bersangkutan untuk bersaing dengan perusahaan lain, terutama dalam usahanya untuk menciptkan suatu produk pelayanan yang lebih murah, lebih baik dan lebih cepat. ${ }^{25}$

Pada catatan penelitian Lallmahamood ditemukan bahwa teknologi perbankan sering menjadi faktor kritis dan menentukan kepuasan nasabah dan kinerja CRM pelanggan. ${ }^{26}$ Bagi pelanggan teknologi yang dimiliki perusahaan merupakan cerminan kinerja perusahaan. ${ }^{27}$ Ismail et, al.,berkesimpulan bahwa kepuasan pelanggan merupakan wujud keberhasilan dapat dicapai oleh perusahaan berdasarkan teknologi. ${ }^{28}$ Teknologi yang bermanfaat dan memiliki keunggulan dalam kemudahan dan kinerja menjadi bagian penting yang harus dimiliki dan disiapkan perusahaan. Sehingga

${ }^{24}$ Wiji Nurastuti, Teknologi Perbankan, (Yogyakarta: Graha Ilmu, 2011), h. 109

${ }^{25}$ Ibid.,

${ }^{26}$ Lallmahamood, Muniruddeen, (2007), " An Examination Of Individual's PerceivedSecurity And Privacy Of The Internet In Malaysia And Influence Of This On Their Intention To Use E-Commerce: Using An Extension Of The Technology Acceptance Model ", Journal Internet Banking and Commerce, Vol. 12 No. 3, h. $1-26$

${ }^{27}$ Ibrahim, Essam E., Matthew Joseph., and, Kevin I.N. Ibeh (2006), " Customers'Perception Of Electronic Service Delivery In The UK Rentail Banking Sector ", International Journal of Bank Marketing, Vol. 24 No. 7 , h. 475-493

${ }^{28}$ Ismail, Hishamuddin Bin., Dilruba Talukder., and, Mohammad Fateh Ali Khan Panni (2007), " Technology Dimension of CRM: The Orientation Level And Ist Impact On The Business Performance of SMEs in Malaysia ", InternationalJournal Electronic Customer Relationship Management, Vol. 1 No. 1, h. 16-28 
Busriadi :Pengaruh Tekonlogi Informasi...

semakin baik pengelolaan teknologi maka semakin tinggi derajad kepuasan pelanggan. ${ }^{29}$

Teknologi merupakan salah satu komponen penting di dalam sebuah perusahaan.Hampir mustahil perusahaan atau organisasi menjalankan usahanya tanpa adanya teknologi di masa sekarang ini.Karena Teknologi sudah menjadi suatu komponen yang tak terpisahkan dari sebuah perusahaan dan merupakan salah satu unsur terpenting dalam menjalankan kegiatan perusahaan.Untuk itu dibutuhkan sumber daya manusia yang menguasai teknologi tersebut.Dengan adanya sumber daya manusia yang menguasai teknologi tersebut maka kualitas produksi suatu perusahaanpun dapat ditingkatkan. Di sisi lain, Teknologi akan sia-sia jika sumber daya manusianya tidak dapat memanfaatkan teknologi tersebut. Oleh sebab itu, keterkaitan antara sumber daya manusia dengan teknologi sangatlah erat.Sehingga dibutuhkan sumber daya manusia yang berkompeten dan mampu menguasai teknologi agar perusahaan dapat berjalan dengan baik.

Berdasarkan rujukan penelitian terdahulu, maka rumusan hipotesis pada penelitian ini adalah sebagai berikut;

\section{H1; Teknologi berpengaruh positip terhadap kepuasan nasabah}

\section{Metode Penelitian}

Jenis Penelitian yang digunakan dalam penelitian ini adalah deskriptif analisis danmetode kuantitatif. Untuk jenis penelitian deskriptif yang digunakan adalah penelitian studi kasus.Menurut Maxfield penelitian studi kasus adalah penelitian tentang status objek penelitian yang berkenaan dengan suatu fase spesifik atau khas dari keseluruhan personalitas yang bertujuan untuk membuat deskripsi secara sistematis, factual dan akurat mengenai fakta dan sifat populasi atau daerah tertentu. ${ }^{30}$ Dalam studi kasus peneliti mengumpulkan informasi yang banyak dan luas mengenai suatu obyek. ${ }^{31}$ sedangkan Metode kuantitatif adalah metode yang digunakan untuk penyajian hasil penelitian dalam bentuk angka-angka atau statistik. Metode kuantitatif juga digunakan untuk menguji hipotesis.

\footnotetext{
${ }^{29}$ Chung, Yi-Chan., Shiaw-Wen Tien., Chih-Hung Tsai., and., Lin-Lin Tang (2007),“An Empirical Study Of Customer Relationship Management Implementation in Taiwan's Machine Industry ”, Business and Public Affairs, Vol. 1, Issue 1. h.1-12

${ }^{30}$ Moh Nazir, Metode Penelitian (Bogor: Ghalia Indonesia, 2005), h.57. h.73.

${ }^{31}$ Hani 'Arab, Maharats At-Tafkir Wa Al-Bahts Al-'Ilmi, (tt: Rendezvous Sientific Researches, 2009),
} 
BUSRIADI :Pengaruh Tekonlogi Informasi...

\section{Hasil Penelitian}

\section{a. Pengertian Pegadaian Syariah}

Pegadaian syariah adalah lembaga keuangan yang menganut sistem gadai yang berlandaskan prinsip-prinsip dan nilai keislaman. ${ }^{32}$ Perusahaan Umum (PERUM) Pegadaian, yang selanjutnya dalam Peraturan Pemerintahdisebut Perusahaan adalah Badan Usaha Milik Negara sebagaimana diatur dalam Undang-undang Nomor 9 Tahun 1969, yang bidang usahanya berada dalam lingkup tugas dan kewenangan Menteri Keuangan, dimana seluruh modalnya dimiliki Negara berupa kekayaan Negara yang dipisahkan dan tidak terbagi atas saham. ${ }^{33}$

Usaha Pergadaian syariah adalah segala usaha menyangkut pemberian pinjaman dengan jaminan barang bergerak, jasa titipan, jasa taksiran, dan/atau jasa lainnya yang diselenggarakan berdasarkan prinsip syariah. Yang dimaksud dengan Prinsip Syariah disini adalah ketentuan hukum Islam berdasarkan fatwa dan/atau pernyataan kesesuaian syariah dari Dewan Syariah Nasional Majelis Ulama Indonesia. ${ }^{34}$

Secara umum teknis lembaga keuangan syariah adalah ${ }^{35}$ :

1) Akad dan aspek legalitas.

Akad yang dilakukan memiliki konsekuensi duniawi dan ukhrawi, karena akad yang dilakukan berdasarkan hukum Islam.Menurut Masudul Alam Choudhory ${ }^{36}$ transaksi dan bisnis dalam akad harus mengacu kepada konsep-konsep fiqh muamalah yang sudah di convergensce dengan sistem ekonomi dan keuangan modern tanpa meninggalkan hukum syariah.

2) Struktur organisasi.

Lembaga keuangan syariah dapat memiliki struktur yang sama dengan dengan lembaga keuangan konvensional, misalnya dalam hal komisaris dan direksi, dan bagian-bagian lainnya, tetapi unsur yang amat membedakan lembaga keuangan syariah dengan lembaga keuangan konvensional adalah keharusan adanya dewan pengawass syariah yang bertugas mengawasi operasional bank dan produkproduknya agar sesuai dengan garis-garis syariah.

\footnotetext{
${ }^{32}$ Fatwa MUI No. 25/DSN-MUI/III/2002

${ }^{33}$ Peraturan Pemerintah Republik Indonesianomor 103 Tahun 2000tentangperusahaan Umum (Perum) Pegadaian

${ }^{34}$ Peraturan Otoritas Jasa KeuanganNomor31 /POJK.05/2016TentangUsaha Pergadaian

${ }^{35}$ Zainuddin Ali, Hukum Ekonomi Syariah (Jakarta: Sinar Grafika, 2008), hal.47.

${ }^{36}$ Faesal Badroen, Etika Bisnis Dalam Islam (Jakarta: Kencana.2007), hal. 141.
} 
Busriadi :Pengaruh Tekonlogi Informasi...

3) Bisnis dan usaha yang dibiayai

Dalam lembaga keuangan syariah, bisnis dan usaha yang dilaksanakan tidak terlepas dari saringan syariah. lembaga keuangan syariah tidak akan mungkin membiayai usaha yang terkandung di dalamnya hal-hal yang diharamkan, mudharat dan bertentangan dengan nilai-nilai Islam.

4) Lingkungan kerja dan Corporate Culture.

Lembaga keuangan syariah yang seharusnya mempunyai lingkungan kerja yang sejalan dengan syariah. dalam hal etika misalnya, sifat siddiq atau amanah, harus melandasi setiap karyawan sehingga tercermin integritas eksekutif muslim yang baik.

Secara khusus teknis pegadaian syariah adalah ${ }^{37}$ :

1) Yang menguntungkan dari Pegadaian Syariah ini,perhitungannya bukan berdasarkan bunga, melainkan sewa tempat.Misalnya Ijaroh: upah atau sewa tempat. Proses gadainya sama. Perhitungan sewa tempat per 10 hari, tetapi yang beda yaitu akad (perjanjian) berdasarkan harga taksiran barang, dan bukan berdasarkan uang pinjaman.

2) Taksiran barang itu bisa dilihat dari golongan barangnya. Penilaian golongan barang biasanya dimulai dari Golongan A hingga Golongan $\mathrm{H}$.

3) Pegadaian Syariah diperuntukkan semua kalangan. Semua orang dapat melakukan transaksi di Pegadaian Syariah, Selain itu, juga akan diadakan program jual logam mulia. Logam mulia yang dimaksud yaitu berupa emas batangan. Untuk emas batangan ini, sistem kreditnya pun dapat diangsur. Pengadaan emas 15 batangan ini terjalin, berkat kerjasama Pegadaian dengan PT. Antam (Aneka Tambang).

\section{b. Keunggulan Pegadaian Syariah}

Pembiayaan Rahn dari Pegadaian Syariah adalah solusi tepat kebutuhan dana cepat yang sesuai syariah. Cepat prosesnya, aman penyimpanannya. Jaminannya barang perhiasan, barang elektronik atau kendaraan bermotor . Lima belas menit dana pun cair, Keunggulan lain diantaranya ${ }^{38}$ :

1) Layanan Rahn tersedia di outlet Pegadaian Syariah di seluruh Indonesia

\footnotetext{
${ }^{37}$ Habiburrahim, Buku Saku Pegadaian Syariah. (Jakarta Timur: Kuwais, 2012), hal.12.

38 www.pegadaian.co.id
} 
BUSRIADI :Pengaruh Tekonlogi Informasi...

2) Prosedur pengajuannya sangat mudah. Calon nasabah atau debitur hanya perlu membawa agunan berupa perhiasan emas dan barang berharga lainnya ke outlet Pegadaian

3) Proses pinjaman sangat cepat, hanya butuh 15 menit

4) Pinjaman (MarhunBih) mulai dari 50 ribu rupiah sampai 200 juta rupiah atau lebih

5) Jangka waktu pinjaman maksimal 4 bulan atau 120 hari dan dapat diperpanjang dengan cara membayar Ijarah saja atau mengangsur sebagian uang pinjaman

6) Pelunasan dapat dilakukan sewaktu-waktu

7) Tanpa perlu buka rekening. dengan perhitungan sewa modal selama masa pinjaman

8) Nasabah menerima pinjaman dalam bentuk tunai.

\section{c. Pedoman Pengoperasionalan Gadai Syariah}

Mekanisme operasional gadai syariah sangat penting untuk diperhatikan karena jangan sampai operasional gadai syariah tidak efektif dan efesien. mekanisme operasional gadai syariah haruslah tidak menyulitkan calon nasabah yang akan meminjam uang atau yang melakukan akad utang piutang.Akad yang dijalankan termasuk jasa dan produk yang dijual juga harus selalu berlandaskan Al-Qur'an, AlHadist, dan Ijma Ulama, dengan tidak melakukan kegiatan usaha yang mengandung unsur riba, maisir, dan gharar. oleh karena itu pengawasannya harus melekat, baik internal terutama keberadaan dewan pengawas syariah (DPS) sebagai penanggung jawab yang berhubungan dengan aturan syariahnya, yaitu yaitu masyarakat muslim utamanya, serta yang tidak kalah pentingnya adalah adanya perasaan selalu mendapatkan pengawasan yang membuat aturan syariah itu sendiri yaitu Allah SWT.

Implementasi operasional pegadaian syariah hampir bermiripan dengan pegadaian konvensional, perbedaan mendasar antara pegadaian syariah dengan pegadaian konvensional terletak pada pengenaan biaya. pada pegadaian konvensional, biaya adalah bunga yang bersifat akumulatif dan berlipat ganda. namun pegadaian syariah biaya ditetapkan sekali dan dibayar dimuka yang ditujukan untuk biaya penitipan, pemeliharaan, penjagaan, dan penaksiran. sepertihalnya pegadaian konvensional pegadaian syariah juga menyalurkan uang pinjaman dengan jaminan benda bergerak. untuk memperoleh pinjaman gadai syariah sangat sederhana, masyarakat hanya menunjukkan identitas diri dan barang bergerak sebagai jaminan. uang pinjaman dapat diperoleh dalam waktu yang relatif tidak lama, begitupun untuk 
Busriadi :Pengaruh Tekonlogi Informasi...

melunasi pinjaman, nasabah cukup menyerahkan sejumlah uang dan surat bukti rahn saja dengan proses dan waktu yang sangat singkat. ${ }^{39}$

Pedoman opersional gadai syariah (POGS) perum pegadaian, pada dasarnya dapat melayani produk dan jasa sebagai berikut ${ }^{40}$ :

1) Pemberian pinjaman atau pembiayaan atas dasar hukum gadai syariah ( rahn) yaitu pegadaian syariah mensyaratkan penyerahan barang gadai oleh nasabah (rahin) untuk mendapatkan uang pinjaman yang besarnya sangat ditentukan oleh nilai barang yang digadaikan.

2) Penaksiran nilai barang. yaitu pegadaian syariah memberikan jasa penaksiran atas nilai suatu barang yang dilakukan oleh calon nasabah (rahin) untuk jasa penaksiran ini hanya memungut biaya penaksiran.

3) Penitipan barang (ijarah) yaitu penyelenggaraan penitipan barang berdasarkan pertimbangan keamanan atau alasan tertentu lainnya. atas jasa penitipan yang dimaksud pegadaian syariah dapat memungut ongkos penyimpanan.

4) Gerai emas yaitu tempat penjualan emas yang menawarkan keaslian dan kualitas. emas yang dijual dilengkapi dengan sertifikat jaminan.

Dimensionalisasi yang dipergunakan dalam mengukur konstruk teknologi adalah sebagai berikutTeknologi yang mudah; Teknologi yang tepat guna; Teknologi yang berfungsi; ragam teknologi.Hubungan variabel dan indikatornya dapat digambarkan dalam gambar dibawah ini :

\section{Gambar 1}

\section{Dimensionalisasi Variabel Teknologi}

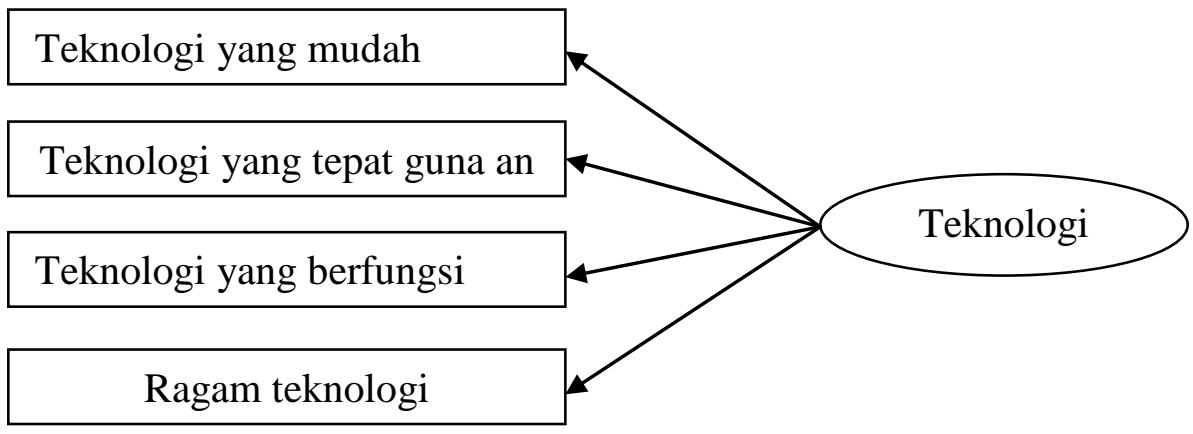

${ }^{39}$ Adriyan Sutedi, Hukum Gadai Syariah (Bandung: CV.Alvabeta, 2011), h. 151

${ }^{40}$ Adriyan Sutedi, Hukum Gadai Syariah, h. 152 
BUSRIADI :Pengaruh Tekonlogi Informasi...

Sumber : Chen, Popovick (2003), Qureshi, et,al.,(2008), Wiji Nurastuti (2011), Lallmahamood (2007).

Dimensionalisasi yang dipergunakan dalam mengukur konstruk kepuasan nasabah adalah sebagai berikutkeramahan karyawan; keamanan dan privasi; fasilitas; kenyamanan.Hubungan variabel dan indikatornya dapat digambarkan dalam gambar dibawah ini :

Gambar 2

Dimensionalisasi Variabel Kepuasan Nasabah

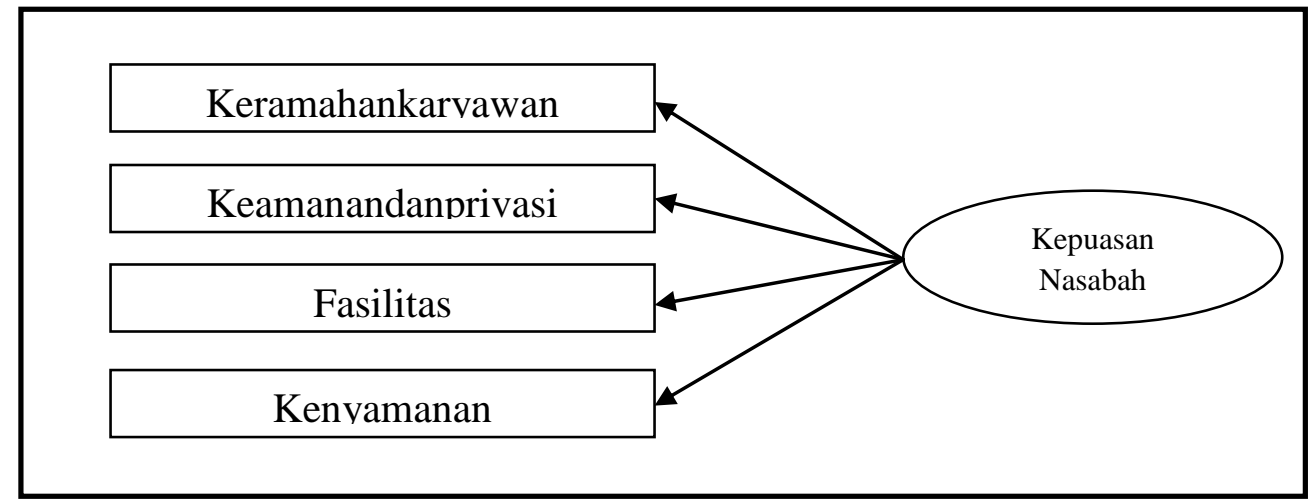

Sumber : Mohrw, Jackson (1991), Muhammad, et.al.,(2016), Sri Widyastuti (2016), Kotler, Keller (2007), Zhou (2004), Liang dan Wang (2007).

Tabel 2.

Hasil Analisis Data

\begin{tabular}{|c|c|c|c|c|c|c|c|}
\hline \multicolumn{8}{|c|}{ Teknologi } \\
\hline $\mathrm{X} 1$ & 0,729 & 0,531441 & $\begin{array}{r}0,53 \\
2\end{array}$ & 0,468 & 9,3574 & 0,8576 & 0,6011 \\
\hline $\mathrm{X} 2$ & 0,766 & 0,586756 & $\begin{array}{r}0,58 \\
6\end{array}$ & 0,414 & & & \\
\hline X3 & 0,729 & 0,531441 & $\begin{array}{r}0,62 \\
7\end{array}$ & 0,373 & & & \\
\hline $\mathrm{X} 4$ & 0,835 & 0,697225 & $\begin{array}{r}0,69 \\
8\end{array}$ & 0,302 & & & \\
\hline Jumlah & 3,059 & 2,346863 & 2,443 & 1,557 & & & \\
\hline \multicolumn{8}{|c|}{ Kepuasan Nasabah } \\
\hline $\mathrm{X} 1$ & 0,644 & 0,414736 & 0,415 & 0,585 & 8,6083 & 0,8245 & 0,5406 \\
\hline
\end{tabular}


Busriadi :Pengaruh Tekonlogi Informasi...

\begin{tabular}{|c|c|c|c|c|}
\hline $\mathrm{X} 2$ & 0,756 & 0,571536 & 0,571 & 0,429 \\
\hline X3 & 0,776 & 0,602176 & 0,602 & 0,398 \\
\hline
\end{tabular}

\begin{tabular}{|l|l|l|l|l|l|l|l|}
\hline & & & Estimate & S.E. & C.R. & P & Label \\
\hline
\end{tabular}

\begin{tabular}{|l|r|r|r|r|r|r|l|l|}
\cline { 5 - 8 } & 0,758 & 0,574564 & 0,574 & 0,426 & & & & \\
\hline Jumlah & 2,934 & 2,163012 & 2,162 & 1,838 & & & & \\
\hline
\end{tabular}

Berdasarkan Tabel tersebut, terlihat bahwa tidak terdapat nilai reliabilitas dan variance extract yang berada di bawah batas nilai yang telah ditetapkan. Dengan demikian dapat disimpulkan bahwa indikator-indikator yang digunakan sebagai observed variable bagi variabel latennya dapat dikatakan telah mampu menjelaskan variabel laten yang dibentuknya.

Hipotesis pada penelitian ini adalah teknologi berpengaruh signifikan terhadap kepuasan nasabah, sehingga semakin tinggi teknologi maka semakin tinggi kepuasan nasabah. Berdasarkan data dari hasil pengolahan data diketahui bahwa nilai CR (Critical Ratio) untuk hubungan antara variabel kompetensi sumber daya manusia seperti terlihat pada Tabel 4.18 adalah sebesar 2,420 dengan nilai P (Probability) sebesar 0,016. Kedua nilai ini menunjukkan hasil yang memenuhi syarat, yaitu di atas 1,96 untuk CR (CriticalRatio) dan di bawah 0.05 untuk nilai P (Probability). Sehingga dapat dapat disimpulkan bahwa hipotesis pada penelitian ini di terima.

Tabel 3

Regression Weights: (Group number 1 - Default model) 
BUSRIADI :Pengaruh Tekonlogi Informasi...

\begin{tabular}{|c|c|c|c|c|c|c|c|}
\hline $\mathrm{X} 1$ & $<---$ & t3 & 1,000 & & & & \\
\hline $\mathrm{X} 2$ & $<--$ & t3 & ,986 & 106 & 9,279 & $* * *$ & par_2 \\
\hline X3 & $<---$ & t3 & 1,014 & ,121 & 8,375 & $* * *$ & par_3 \\
\hline $\mathrm{X} 4$ & $<---$ & t3 & ,986 & 127, & 7,755 & $* * *$ & par_4 \\
\hline $\mathrm{X} 1$ & $<---$ & KN4 & 1,000 & & & & \\
\hline $\mathrm{X} 2$ & $<--$ & KN4 & 1,114 & 170 & 6,571 & $* * *$ & par_2 \\
\hline X3 & $<---$ & KN4 & 1,330 & 200 & 6,661 & $* * *$ & par_3 \\
\hline $\mathrm{X} 4$ & $<---$ & KN4 & 1,238 & 192 & 6,435 & $* * *$ & par_4 \\
\hline
\end{tabular}

\section{Penutup}

Hipotesis yang diajukan pada penelitian ini adalah mutu pelayanan berpengaruh positif dan signifikan terhadap kepuasan nasabah. Berdasarkan hasil analisis data maka penelitian ini berhasil membuktikan dan selanjutnya menyimpulkan bahwa mutu pelayanan berpengaruh positif terhadap kepuasan nasabah, sehingga semakin tinggi mutu pelayanan maka semakin tinggi kepuasan nasabah. Selanjutnya dari peryataan hipotesis tersebut penelitian ini dapat menyimpulkan bahwa; Hipotesis yang dibangun dalam penelitian ini memperkuat justifikasi hipotesis penelitian terdahulu,di mana mutu pelayanan berpengaruh terhadap kepuasan pelanggan.

\section{DAFTAR PUSTAKA}

Adriyan Sutedi, Hukum Gadai Syariah, Bandung: CV.Alvabeta, 2011.

Agus Sulastiyono, Manajemen Penyelenggaraan Hotel. Bandung: Alfabeta, 2008.

Ariani Wahyu D, Manajemen Operasi Jasa, Yogyakarta: Graha Ilmu, 2009.

Cronin, J. Joseph Jr. dan Taylor, Steven. 1992. “Measuring Service Quality :Reex Amination and Extension" Journal of Marketing.Vol. 56.

Dash, Satyabhusan., Ed Bruning., and, Kalyan Ku Guin, 2006. " The Moderating Effect Of Power Distance On Perceived Interdependence And Relationship Quality In Commercial Banking ", International Journal of Bank Marketing, Vol. 21, No. 5.

Faesal Badroen, Etika Bisnis Dalam Islam, Jakarta: Kencana.2007.

Fatwa MUI No. 25/DSN-MUI/III/2002

G. Armstrong and P. Kotler, Marketing: An Introduction, Pearson Education, Upper Saddle River, NJ, USA, 10th edition, 2011. 
Gounaris, Spiros P., Vlassis Stathakopoulos., and, Antreas D. Athanassopoulos, 2003." Antecedents to Perceived Service Quality: An Exploratory Study In The Banking Industry ", International Journal of Bank Marketing, Vol. 21 No. 4.

Habiburrahim, Buku Saku Pegadaian Syariah. Jakarta Timur: Kuwais, 2012.

Hani 'Arab, Maharats At-Tafkir Wa Al-Bahts Al-'Ilmi, tt: Rendezvous Sientific Researches, 2009.

Herry Ahmad Buchory dan Djaslim Saladin, Dasar-Dasar Pemasaran Bank, (Bandung: Linda Karya, 2006.

Herry Sutanto dan Khaerul Umam, Manajemen Pemasaran Bank Syariah. Bandung: Pustaka Setia, 2013

http://www.ojk.go.id/id/regulasi/otoritas-jasa-keuangan/peraturan ojk/POJK-UsahaPergadaian.pdf

https://www.ojk.go.id/id/kanal/iknb/datadan-statistik 29 Mei 2019. Diakses pada tanggal 29 Juni 2019

Inggang Perwangsa, Nuraalam, Manajemen Hubungan Pelanggan Perbankan Syariah Indonesia. Sleman : CV Budi Utama, 2018.

Irawan Handi, 10 Prinsip Kepuasan Pelanggan, Jakarta: Elex Media, 2007.

Jones, Tim., and, Shirley F. Taylor, 2007. " The Conceptual Domain Of Service Loyalty: How Many Dimensions ", Journal of Service Marketing, Vol. 21 No. 1.

Kang, Gi-Du, "The Hierarchical Structure Of Service Quality: Integration Of Technical And Functional Quality", Managing Service Quality, vol. 16 No. 1, 2006.

Kasim, Mohd Norizan., and Abdel Kader Mohammed Ahmed Abdulla (2006) " The Influence of Attraction On Internet Banking: An Extension To The Trustrelationship Commitment Model ", International Journal of Bank Marketing, Vol. 24 No. 6.

Kotler, Philip. dan Keller, Kevin Lane. Manajemen Pemasaran. Jilid 1dan 2. Jakarta: PT Indeks, 2007.

Kotler, Phillip \& Garry Armstrong, Principles of Marketing. 11 th Edition, Prentice Hall International Inc. New Jersey. 2006.

Lovelock, et. al., Pemasaran Jasa Manusia, Teknologi, dan Strategi. Jakarta: Erlangga, 2010.

Moenir, Manajemen Pelayanan Umum Di Indonesia, Jakarta, Bumi Aksara, 2002.

Moh Nazir, Metode Penelitian. Bogor: Ghalia Indonesia, 2005

Payne, A, Handbook of CRM: Achieving Excellence in Customer Management. Great Britain: Elsevier Ltd. 2008.

Peraturan Otoritas Jasa Keuangan Nomor 31 /POJK.05/2016 Tentang Usaha Pergadaian

Peraturan Pemerintah Republik Indonesianomor 103 Tahun 2000 tentang perusahaan Umum (Perum) Pegadaian

Philip Khotler,dkk, Dasar-Dasar Pemasaran, Jakarta: Indonesia, 1996. 
BUSRIADI :Pengaruh Tekonlogi Informasi...

Sari dan Irine Diana.Manajemen Pemasaran Usaha Kesehatan, Yogyakarta: Mitra Cendikia Offset, 2008.

Sharma, Alka., and Versha Mehta (2005), " Service Quality Perceptions In Financial Service-A Case Study Of Banking Services ", Journal of Service Research, vol. 4, 2005.

Sri Widyastuti, Membina Keakraban Pelanggan: Manajemen Hubungan Pelanggan Sejati, Jakarta Selatan: Fakultas Ekonomi dan Bisnis Universitas, 2016.

Sutrino, Edy.Budaya Organisasi, Jakarta: Kencana Prenada Media Group, 2010.

Tim Markenis. Customer Satisfaction and Beyond, Yogyakarta: Markenis, 2009.

Tjiptono Fandy dan Chandra, Gregorius.Service, Quality, Satisfaction. Yogyakarta: Andi, 2007.

Tjiptono, Fandy, Pemasaran Jasa. Malang: Bayu Media Publishing, 2006.

Tseng, Yi Ming, 2007, " The Impacts Of Relationship Marketing Tactics On Relationship Quality In Service Industry ", The Business Review, Vol. 7 No. 2.

Ueltschy, et. al., " Service Quality And Satisfaction: An International Comparison of Professional Services Perceptions “, Journal of Services Marketing, Vol. 21 No. 6. 2007.

Yap, Kenneth B., and, Jillian C. Sweeney, 2007. " Zone-Of-Tolerance Moderates The Service Quality-Outcome Relationship " Journal of Service Quality, Vol. 21 No. 2.

Zahay, Debra., and, Abbie Griffin, 2004. " Customer Learning Processes, Strategy Selection, And Performance In Business To Business Service Firms " Decision Sciences, Vol. 35 No. 2.

Zainuddin Ali, Hukum Ekonomi Syariah, Jakarta: Sinar Grafika, 2008.

Zainuddin Ali, Hukum Perbankan Syariah, Jakarta: Sinar Grafika, 2008

www.ojk.go.id

www.pegadaian.co.id 